\title{
SÍNTESE DO 2-ALIL-4-CLORO-6-ISOPROPIL-3-METILFENOL A PARTIR DO TIMOL
}

\author{
Ana Flávia Azevedo' \\ Luan I. R. Rocha ${ }^{2}$ \\ Patrícia F. Pinheiro ${ }^{3}$ \\ Luciana A. Parreira ${ }^{4}$ \\ Luciano Menini ${ }^{5}$
}

Resumo: A industria agroquímica busca apresentar compostos cada vez mais eficientes, seletivos e seguros sob a perspectiva ambiental. Nesse contexto, a sintese de novos compostos ativos partindo de materia-prima natural apresenta-se como forte alternativa. Os sistemas catalíticos, que utilizam condições suaves de temperatura e pressão e apresentam grande rendimento mostram-se extremamente eficientes e tem conquistado seu espaço nas pesquisas agroquimicas, bem como a sintese de clorofenois usando ions cloreto como fonte de cloro e um oxidante adequado. O presente trabalho propos sintetizar um composto inédito análogo ao herbicida dicamba, partindo do timol, um fenol de origem natural. Seguindo uma rota de sintese em tres etapas, que teve rendimento global de $84 \%$ pode-se desenvolver o composto 2-alil-4-cloro6-isopropil-3-metilfenol, que foi caracterizado por espectrometria de massas e infravermelho.

Palavras-chave: Catálise; Organoclorados; Timol.

\footnotetext{
${ }^{1}$ Instituto Federal do Espírito Santo, Brasil. E-mail: anaflavia.mulinari@gmail.com.

2 Instituto Federal do Espírito Santo, Brasil. E-mail: luanitalo@hotmail.com.

3 Universidade Federal do Espírito Santo, Brasil. E-mail: patriciafontespinheiro@yahoo.com.br.

${ }^{4}$ Universidade Federal do Espírito Santo, Brasil. E-mail: luaparreira@hotmail.com.

5 Instituto Federal do Espírito Santo, Brasil. E-mail: Imenini@ifes.edu.br.
} 